\title{
Burrowing and Huddling in Newborn Porcupine: The Effect on Thermoregulation
}

\author{
A. HAIM, ${ }^{\wedge}$ R. J. VAN AARDE AND J. D. SKINNER \\ Mammal Research Institute, The University of Pretoria, Pretoria 0002, South Africa
}

Received 17 September 1991

\begin{abstract}
HAIM, A., R. J. VAN AARDE AND J. D. SKINNER. Burrowing and huddling in newborn porcupine: The effect on thermoregulation. PHYSIOL BEHAV 52(2) 247-250, 1992.-The newborn cape porcupine IIvstrix africaeaustralis is a precocial rodent. However, the newborn spends its first 9 weeks in the burrow. Heat production (oxygen consumption $-\dot{V}_{\mathrm{O}_{2}}$ ) and body temperature $\left(T_{\mathrm{b}}\right)$ were measured at various ambient temperatures $\left(T_{\mathrm{a}}\right)$ in newborn (4-8-week-old) porcupines, with a body mass between 1340-1993 g during summer, from the colony kept at the Mammal Research Institute, University of Pretoria. To assess the effect of huddling, these parameters were also measured in adult pairs of porcupines $\left(T_{\mathrm{a}}=15\right.$ and $\left.25^{\circ} \mathrm{C}\right)$ kept together in the metabolic chamber and the values were compared with those obtained from single porcupines. Overall minimal thermal conductance was calculated for newborn and paired adult porcupines. The newborn porcupines can regulate their body temperature at $T_{\mathrm{a}} \mathrm{s}$ between $10-28^{\circ} \mathrm{C}$. $\dot{V}_{\mathrm{O}_{2}}$ measured at lower critical point is $0.602 \pm 0.08 \mathrm{ml} / \mathrm{O}_{2} / \mathrm{g} \cdot \mathrm{h}$. At $T_{\mathrm{a}}=10^{\circ} \mathrm{C}, \dot{V}_{\mathrm{O}_{2}}$ oscillated with a characteristic amplitude and frequency, while body temperature was well regulated. Huddling decreases the lower critical point. The overall minimal thermal conductance $\left(0.044 \pm 0.002 \mathrm{ml} \mathrm{O} / \mathrm{g} \cdot \mathrm{h} \cdot 1^{\circ} \mathrm{C}\right)$ is higher than expected from body mass, so that the young are liable to lose heat rapidly. It is well known that the newborn porcupine spends a long period in the burrow and the results of this study suggest that this may be in order to conserve energy and presumably allocate it to growth. Apart from decreasing vulnerability, delaying foraging also avoids heat loss in the newborn porcupine.
\end{abstract}

Thermoregulation Energy allocation Huddling Newborn hystricomorph rodent Metabolic rate

THE increased ratio of surface area to mass in a small-sized mammal is clearly reflected in the newborns, which are very sensitive to cooling. This tendency diminishes progressively as the newborn mammal grows. The studies carried out on thermoregulation of young mammals were reviewed by Hull (11), while aspects concerning thermoregulation of newborn polar homeotherms were reviewed by Blix and Steen (2). Aspects of thermoregulation and metabolic rates were also studied in mammals from warm regions; for instance, the hyrax Procavia capensis from the Southern African subregion (16).

The Cape porcupine Hystrix africaeaustralis, which is the largest Southern African rodent, is widely distributed in the subregion. This nocturnal species has a wide ecological tolerance $(5,20)$. The newborn Cape porcupine is a precocious offspring; it is born with open eyes, the body is covered with short spines, and the back quills are soft at birth. The young are born in grasslined nesting holes. In one litter there can be between 1-3 young porcupines, and a difference in body mass is noted between the sibling neonates. The average body mass is about $300 \mathrm{~g}$. Until weaning at about 12 weeks, the young can increase body mass at a rate of up to $50 \mathrm{~g} /$ day (20).

As in many other mammals, the newborn porcupine is attached to its mother for suckling but, under natural conditions, it also spends many hours of the day with its parents in the burrow sleeping during daytime (20). At 8-9 weeks, after the quills have developed, the young porcupines leave their burrow and accompany the male on foraging explorations (5).

In the summer rainfall regions, porcupines are born during the warm and wet months from August to March, while Van Aarde (personal communication) noted that in captivity porcupines breed throughout the year.

Extensive research has been carried out in the last decade on various biological topics of this species (21). Recently, metabolic and thermoregulatory aspects of this species were studied $(7,8)$, and it was noted that the metabolic rates of the adult porcupine, acclimated to an ambient temperature of $25^{\circ} \mathrm{C}$ with a photoperiod of $12 \mathrm{~L}: 12 \mathrm{D}$, are only $57 \%$ of that expected for its body mass (12). However, so far no data have been published on these topics in the newborn Cape porcupine. Heat production and temperature regulation in precocial and altricial rodents have been compared $(22,23)$. Although the newborn porcupine is a precocial rodent, it stays in its nest site for a very long period (8-9 weeks) before it forages above ground. Therefore, it seems to be an interesting animal in which to study thermoregulatory abilities.

The aim of this study was to investigate the metabolic and thermoregulatory abilities of the newborn precocial Cape porcupines at different ambient temperatures, and to assess the role of burrowing and huddling in temperature regulation of this species.

\footnotetext{
${ }^{1}$ Requests for reprints should be addressed to Dr. Abraham Haim, Oranim, University of Haifa, P.O. Tivon 36910, Israel.
} 
METHOD

The study was carried out on four porcupines, 1-2 months old, with a body mass of 1350-1900 g. Measurements were carried out from mid-November to the end of December 1986 at the Mammal Research Institute, University of Pretoria. The young porcupines were taken from the colony kept in the experimental farm (University of Pretoria) and were returned to the colony immediately after measurements.

Oxygen consumption $\left(\dot{V}_{\mathrm{O}_{2}}\right)$ was measured in the young porcupines at ambient temperatures $\left(T_{\mathrm{a}}\right)$ between $10-30^{\circ} \mathrm{C}$, using an open flow system $(6,10)$, in a metabolic chamber with a volume of 4.8 liters. $\dot{V}_{\mathrm{O}_{2}}$ was monitored on an Ametek S-3A/II (Applied Electrochemistry) oxygen analyzer. A flow of air, dried over silica gel (uniLAB), at a rate of $1300 \mathrm{ml} / \mathrm{min}$ was used. $\dot{V}_{\mathrm{O}_{2}}$ was recorded for a minimal period of $30 \mathrm{~min}$ after a $2-3 \mathrm{~h}$ period of stabilizing in the metabolic chamber at each $T_{\mathrm{a}}$. The average resting metabolic rate (RMR) was calculated from readings, recorded every 3 min during the recording period. Because of fluctuations in readings during the recording period at $T_{\mathrm{a}}=$ $10^{\circ} \mathrm{C}, \dot{V}_{\mathrm{O}_{2}}$ was also calculated for every reading.

For measuring the metabolic and thermoregulatory effects of huddling, adult porcupines acclimated to $T_{\mathrm{a}}=25^{\circ} \mathrm{C}$ with a photoperiod of $12 \mathrm{~L}: 12 \mathrm{D}$ were used. $\dot{V}_{\mathrm{O}_{2}}$ was measured as in Haim et al. (7), except that two sibling porcupines were kept in the metabolic cage. Such measurements were carried out at $T_{\mathrm{a}}$ $=15$ and $25^{\circ} \mathrm{C}$, and the results were compared with those measured for each porcupine kept singly.

All $\dot{V}_{\mathrm{O}_{2}}$ measurements were carried out during the light phase and all results were corrected to standard conditions (STPD).

Body (rectal) temperature $\left(T_{\mathrm{b}}\right)$ of the newborn porcupines was measured at the beginning and at the end of each $\dot{V}_{\mathrm{O}_{2}}$ measurement, using a chromel-alumel thermocouple connected to a $52 \mathrm{~K} / \mathrm{J}$ Fluke thermometer. Body temperature of the adult porcupines was measured by using the same methods as in Haim et al. (7).

Below the lower critical temperature, overall minimal thermal conductance for the newborn porcupines was calculated, using the formula of Scholander et aI. (18), as given by Hart (9): $C=$ $M / T_{\mathrm{b}}-T_{\mathrm{a}} ;\left(M\right.$, rate of metabolism $\left.=\dot{V}_{\mathrm{O}_{2}}\right)$.

All measurements were carried out during daytime. All results are given as mean and standard deviation. Student's $t$-test was used to determine significant differences.

RESULTS

The lower critical point $T_{1 \mathrm{c}}$ for the newborn porcupines is at an ambient temperature of $28^{\circ} \mathrm{C}$. Body temperature at $T_{\mathrm{lc}}$ is $38.5 \pm 0.6^{\circ} \mathrm{C}$ with an oxygen consumption of $0.602 \pm 0.08 \mathrm{ml}$ $\mathrm{O}_{2} / \mathrm{g} \cdot \mathrm{h}$. Body temperature is well regulated between $10-28^{\circ} \mathrm{C}$, while at ambient temperature of $30^{\circ} \mathrm{C}$, hyperthermia was observed and $T_{\mathrm{b}}$ increased to $39.0 \pm 0.3^{\circ} \mathrm{C}$ (Fig. 1). At $T_{\mathrm{a}}=10^{\circ} \mathrm{C}$, $\dot{V}_{\mathrm{O}_{2}}$ values, calculated at intervals of $3 \mathrm{~min}$, show oscillations with a characteristic amplitude and frequency. The amplitude of fluctuations was $0.4 \mathrm{ml} \mathrm{O} / \mathrm{g} \cdot \mathrm{h}$, the frequency being $1.4 \pm$ $0.2 \mathrm{~h}^{-1}$ (Fig. 2). Overall minimal thermal conductance of the newborn porcupine, calculated below the lower critical point, had a value of $0.044 \pm 0.002 \mathrm{ml} / \mathrm{g} \cdot \mathrm{h} \cdot 1^{\circ} \mathrm{C}$.

The $\dot{V}_{\mathrm{O}_{2}}$ and $T_{\mathrm{b}}$ values measured for two porcupines kept together in the metabolic cage are given in Fig. 3. The results show that at $15^{\circ} \mathrm{C}$, nonspecific $\dot{V}_{\mathrm{O}_{2}}$ values of two porcupines are the same as those of a single porcupine at $25^{\circ} \mathrm{C}$. A significant increase is noted in $C$ values $\left(C=0.023 \pm 0.003 \mathrm{ml} \mathrm{O}_{2} / \mathrm{g} \cdot \mathrm{h} \cdot{ }^{\circ} \mathrm{C}\right)$ at $T_{\mathrm{a}}=25^{\circ} \mathrm{C}$ for the two porcupines kept in a cage when compared with a single porcupine $(C=0.016 \pm 0.002)$ kept under the same conditions. At $T_{\mathrm{a}}=15^{\circ} \mathrm{C}$, the value of $\mathrm{C}$, calculated
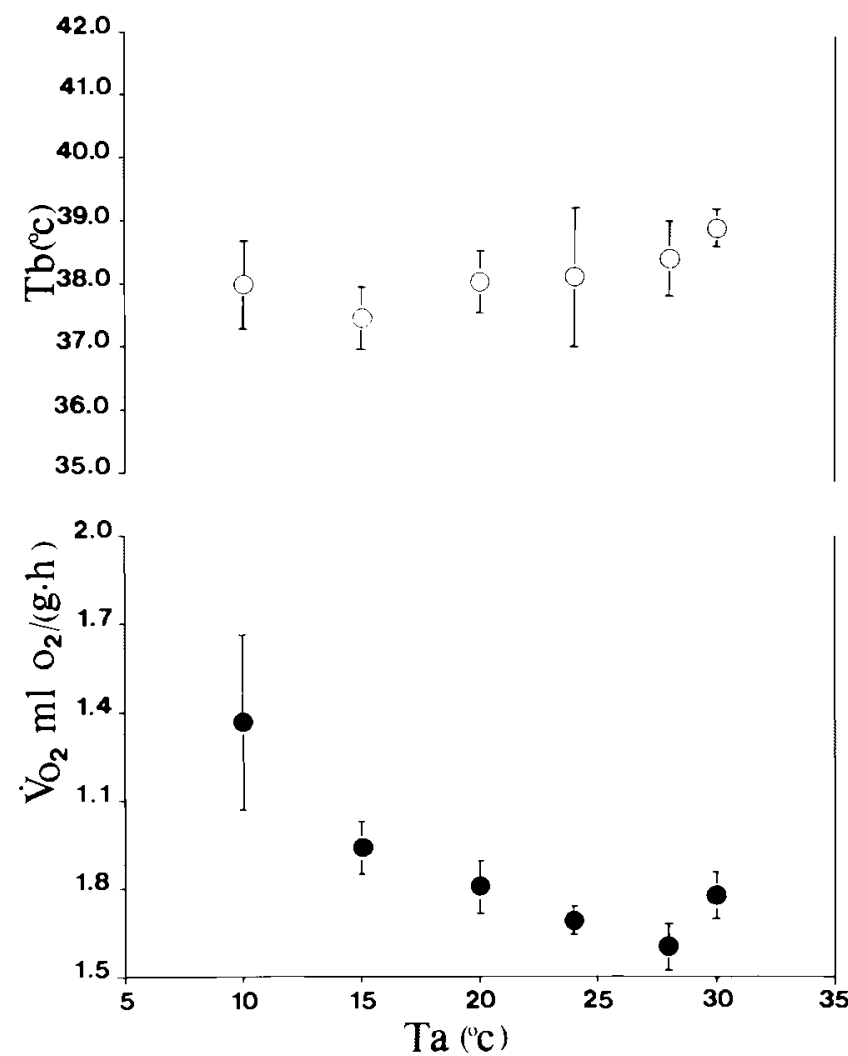

FIG. 1. Oxygen consumption $\left(\dot{V}_{\mathrm{O}_{2}}\right)$ and body temperature $\left(T_{\mathrm{b}}\right)$ of newborn porcupines $H_{1}$ strix africueaustralis at different ambient temperatures $(T)$. Measurements were carried out during November and December 1986 (summer acclimatization). All results are given as mean \pm $\mathrm{SD}$ of $n=4$

for two porcupines kept in a cage was $0.014 \pm 0.001 \mathrm{ml} \mathrm{O}_{2} /$ $\mathrm{g} \cdot \mathrm{h} \cdot{ }^{\circ} \mathrm{C}$, while for a single porcupine the value calculated at $T_{\mathrm{a}}$ $=15^{\circ} \mathrm{C}$ was $0.017 \pm 0.002 \mathrm{ml} \mathrm{O} / \mathrm{g} \cdot \mathrm{h} \cdot{ }^{\circ} \mathrm{C}$.

\section{DISCUSSION}

Newborn mammals have some features in common: they have a larger exposed surface area in relation to body mass as well as less insulation and a high lower critical temperature when compared with the adults (2). These features may cause thermoregulatory problems for the newborn porcupine which, although it is a precocial offspring, it spends up to 9 weeks in the burrow without leaving it to forage. Thus, it is logical to assume that the high energetic demands due to increased heat production and growth must be provided by the lactating mother, while physiological and behavioral adaptations of the newborn conserve energy expenditure as much as possible. Following the parents on foraging trips would be risky not only because of predation, as the quills protect only $8-9$ weeks after birth (20), but may also dissipate a great amount of heat to the environment which, in turn, would increase food demands.

Clarke and Brander (4) showed that in the New World porcupine Erethizon dorsatum, the loss of radiant heat from the heavily quilled rosette area is significantly higher than from other parts covered with more hair. They concluded that quills alone are poor insulation. Therefore, the newborn porcupine, which has neither much hair or heavy quills, may remain in the burrow for a long time because of poor insulation and the large relative 


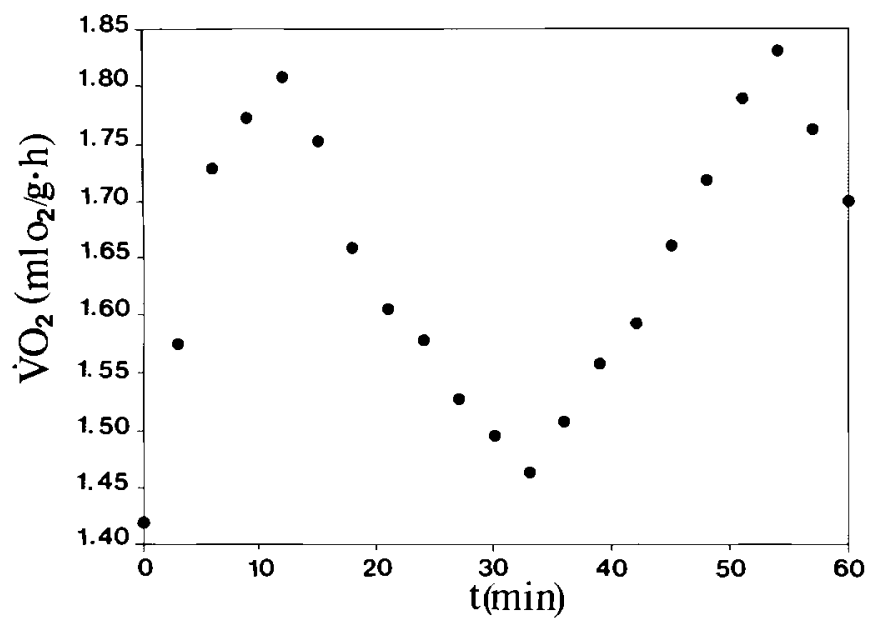

FIG. 2. Oxygen consumption $\left(\dot{V}_{\mathrm{O}_{2}}\right)$ measured in newborn porcupine

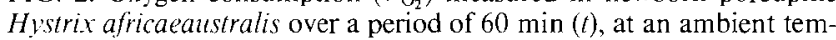
perature $\left(T_{\mathrm{a}}\right)$ of $10^{\circ} \mathrm{C}$

area of exposed surface, although this does not preclude other advantages resulting from this behavior. Hull (11) states that the capacities for thermoregulation in young as well as in adult mammals are limited by their area of exposed surface, which is relatively higher in smaller mammals.

The results of this study show that overall minimal thermal conductance of the few weeks old porcupine is $35 \%$ higher than the value expected for a mammal with a body mass of $1567 \mathrm{~g}$ according to the Bradley and Deavers equation (3). Thus, it seems that the newborn porcupine, with its poor insulation, protects itself from heat loss by using the nest for the relatively long period of 9 weeks. High values of thermal conductance have also been recorded for the juveniles of other species, e.g., hyrax, Procavia capensis (16), and the reindeer Rangifer tarandis tarandus (14).

As in other newborn mammals (11), the lower critical point $\left(T_{\mathrm{lc}}\right)$ for newborn porcupines is higher by $4^{\circ} \mathrm{C}$ than that of the adult porcupine (7). However, $\dot{V}_{\mathrm{O}_{2}}$ measured at the thermoneutral zone is the same as predicted for an adult mammal with a body mass of $1567 \mathrm{~g} 0.602 \mathrm{ml} \mathrm{O}_{2} / \mathrm{g} \cdot \mathrm{h},(10 \mathrm{ml} \mathrm{O} / \mathrm{kg} \cdot \mathrm{min})$. The maximal $\dot{V}_{\mathrm{O}_{2}}$ value measured in newborn rabbits and guinea pigs is $70 \mathrm{ml} \mathrm{O}_{2} / \mathrm{kg} \cdot \min (11)$. The values measured in this study may not be maximal $\left(T_{\mathrm{a}}=10^{\circ} \mathrm{C}\right)$, and the newborn porcupine has a body mass 10 -fold higher than that of a newborn rabbit or guinea pig. As newborn mammals are expected to have a higher specific metabolic rate than adults, the results obtained in this study may suggest why the newborn porcupine stays in its burrow for such a long period. Emerging at an earlier stage from the burrow would transfer energy from the avenue of growth to heat production for thermoregulation and activity; staying in the burrow can allow most of the energy to be allocated to growth.

Energy allocation in newborn rodents is under discussion. A comparative thermoregulatory study between altricial and precocial newborn rodents was carried out. The precocial newborn cotton rat, Sigmodon hispidus, has a high metabolism and a rapid growth. This result does not support the theory of energy allocation in newborn mammals (23). Yet, from an earlier study on these two species, allocation of energy for growth and for development of homeothermy was suggested (15).

In our study, the newborn porcupine increased its body mass between birth and 8 weeks at an average rate of about $25 \mathrm{~g} /$ day.
During this period, under natural conditions the newborn porcupine is still in its burrow and the main increase in body mass, $50 \mathrm{~g} /$ day, begins only after 12 weeks while it is foraging above ground (20). In the case of the newborn porcupine, it seems as if energy is contributed to high metabolism and to rapid growth as suggested for the cotton rat (23). In the adult porcupine, metabolism decreases and RMR values are only $57 \%$ of the expected (7) from its body mass according to Kleiber's equation (12).

A nonsteady-state of $\dot{V}_{\mathrm{O}_{2}}$ and $T_{\mathrm{b}}$ was reported in the shrew Crocidura monach (17). The oscillation frequency of $17.1 \pm 0.2$ $\mathrm{h}^{-1}$, with a deviation of $\dot{V}_{\mathrm{O}_{2}}$ values of $0.4 \pm 0.03 \mathrm{ml} \mathrm{O} / \mathrm{g} \cdot \mathrm{h}$ were recorded at $T_{\mathrm{a}}=17^{\circ} \mathrm{C}$. The oscillation in $\dot{V}_{\mathrm{O}_{2}}$ was accompanied by an oscillation in $T_{\mathrm{b}}$. Using such an oscillation was found to be an efficient mechanism for reducing heat loss in the shrew.

Similarly, when exposed to $T_{\mathrm{a}}=10^{\circ} \mathrm{C}$, the newborn porcupine did not reach a steady-state and $\dot{V}_{\mathrm{O}_{2}}$ rates oscillated (Fig. 2). As availability of energy prior to weaning is a limiting factor (22), $\dot{V}_{\mathrm{O}_{2}}$ oscillationswith a characteristicamplitude and frequencycan be an important mechanism for energy conservation. Thus, the newborn porcupine, when left alone in its burrow, may use a pattern which conserves energy but also avoids hypothermia.

The role of huddling in energy conservation was studied in several rodent species $(1,13,19,24)$. Even under captive conditions the adult porcupines tend to huddle, one individual tending to orientate its head towards the back parts of the other. The newborn porcupines in the colony are frequently in direct contact with their parents, and under natural conditions they spend many hours with their parents in the burrow (20). When two porcupines were kept together in the metabolic chamber, they huddled. Their lower critical point was reduced and at $T_{\mathrm{a}}=15^{\circ} \mathrm{C}, \dot{V}_{\mathrm{O}_{2}}$ was lower than that of a single individual at $25^{\circ} \mathrm{C}(7)$. The ambient temperature of the porcupine burrow is in the range of $14-17^{\circ} \mathrm{C}$. Therefore, it may be assumed that huddling is an important mechanism for reducing energy expenditure in the newborn porcupine.

The results of our study suggest that the long period spent by the newborn porcupines in their burrow, up to 9 weeks after birth, is mainly, but not exclusively, for conserving energy. During daytime they are warmed up by their parents while at night,

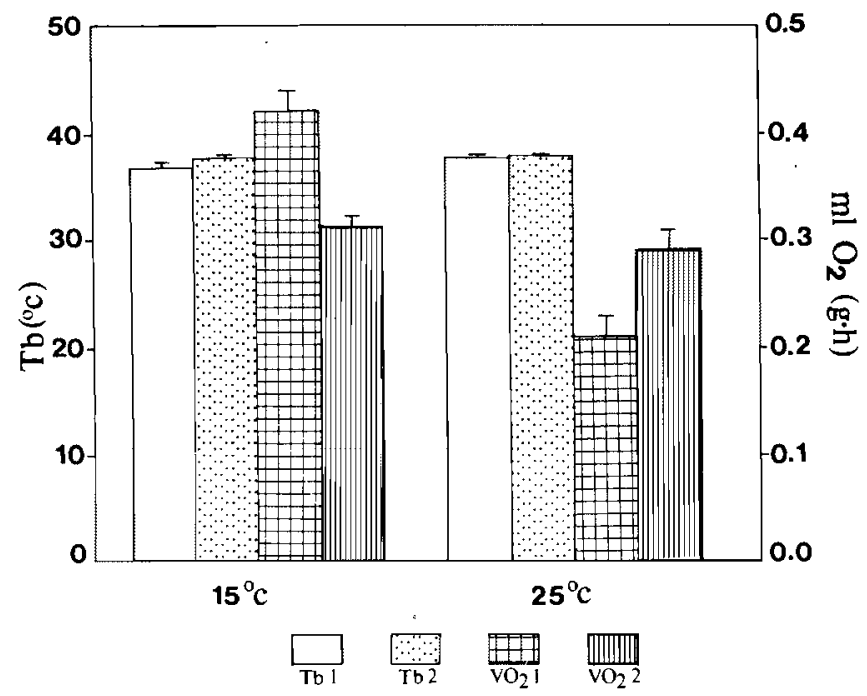

FIG. 3. $T_{\mathrm{bl}}$ and $\dot{V}_{\mathrm{O}_{2}} 1$-body temperature and oxygen consumption measured in a single porcupine. $T_{\mathrm{b} 2}$ and $\dot{V}_{\mathrm{O}_{2}} 2$-body temperature and oxygen consumption measured in sibling porcupines kept in the same metabolic cage. Results are given as mean \pm SD for $n=3$. 
when the parents are foraging, they can decrease $\dot{V}_{\mathrm{O}_{2}}$ by a regulated oscillating mechanism. This behavior pattern of delaying foraging, which contributes to energy conservation, could have been selected because it also fits well with decreasing the vulnerability of the newborn porcupines as they lack sufficient protection until they are 8-9 weeks old.

\section{ACKNOWLEDGEMENTS}

The research was supported by a grant from the Council for Scientific and Industrial Research. The authors thank Messrs. Martin Haput and Edward O'Neill for their technical assistance. We also thank Dr. Joy Hoffmann and the anonymous referee for their important remarks on the manuscript.

\section{REFERENCES}

1. Andrews, R. V.; Belknap, R. W. Bioenergetic benefits of huddling by deer mice (Peromyscus maniculatus). Comp. Biochem. Physiol. $85 \mathrm{~A}: 775-778 ; 1986$.

2. Blix, A. S.; Steen, J. B. Temperature regulation in newborn polar homeotherms. Physiol. Rev. 59:285-304: 1979.

3. Bradley, S. R.; Deavers, D. R. A re-examination of the relationship between thermal conductance and body weight in mammals. Comp. Biochem. Physiol. 65A:465-476; 1980.

4. Clarke, S. H.; Brander, R. B. Radiometric determination of porcupine surface temperature under two conditions of overhead cover. Physiol. Zool. 46:230-237; 1973

5. De Graaff, G. The rodents of Southern Africa, Durban: Butterworths; 1981.

6. Depocas, F.; Hart, J. S. The use of the Pauling Oxygen Analyzer for measurements of oxygen consumption of animals in open-circuit system, and the short-lag closed-circuit apparatus. J. Appl. Physiol. 10:388-392; 1957

7. Haim, A.; Van Aarde, R. J.; Skinner, J. D. Metabolism and thermoregulation in the Cape porcupine, Hystrix africaeaustralis. Physiol. Zool. 63:795-802; 1990.

8. Haim, A.; Van Aarde, R. J.; Skinner, J. D. Metabolic rates, food consumption and thermoregulation in seasonal acclimatization of the Cape porcupine Hystrix africacaustralis. Oecologia 83:197-200; 1990.

9. Hart, J. S. Rodents. In: Whittow, C. G.. ed. Comparative physiology of thermoregulation, vol II. New York: Academic Press; 1971:1149.

10. Hill, R. W. Determination of oxygen consumption by use of the paramagnetic oxygen analyzer. J. Appl. Physiol. 33:261-263; 1972.

11. Hull, D. Thermoregulation in young mammals. In: Whittow, C. G. ed. Comparative physiology of thermoregulation, vol III. New York: Academic Press; 1973:167-200.

12. Kleiber, M. The fire of life. New York: Wiley; 1961:177-216.

13. Madison, D. Group nesting and its ecological and evolutionary significance in overwintering microtine rodents. In: Merritt, J. F., ed.
Winter ecology of small mammals. Spec. Publ. Carnegie Museum Natural History: 1984:267-274

14. Markussen. K. A.; Rognmo, A.; Blix, A. S. Some aspects of thermoregulation in newborn reindeer calves (Rangifer tarandus tarandus. . Acta Physiol. Scand. 123:215-220; 1985.

15. McCluer, P. A.; Randolph, J. C. Relative allocation of energy to growth and development of homeothermy in the eastern wood rat (Neotoma floridana) and the hispid cotton rat (Sigmodon hispidus). Ecol. Monogr. 50:199-219; 1980

16. McNairn, I. S.; Fairall, N. Metabolic rate and body temperature of adult and juvenile hyrax (Procavia capensis). Comp. Biochem. Physiol. 79A:539-545; 1984.

17. Mover, H.; Ar, A.; Hellwing, S. Non-steady-state $\mathrm{O}_{2}$ consumption and body temperature in the shrew Crocidura russula monach (Soricidae, Insectivora). Physiol. Zool. 59:369-375; 1986.

18. Scholander, P. F.: Hock, R.: Walters, V.: Irving, L. Adaptations to cold in arctic and tropic mammals and birds in relation to body temperature, insulation, and basal metabolic rate. Biol. Bull. 99: $259-271: 1950$

19. Selander, J. A., Jr. The relationship of nest protection and huddling to survival of Peromyscus at low temperature. Ecology 33:63-71 1952.

20. Smithers, R. H. N. The mammals of the Southern-African subregion. Pretoria: University of Pretoria; 1983

21. Van Aarde, R. J. Reproduction in the Cape porcupine, Hystrix af ricacaustralis an ecological prespective. S.A. J. Science 83:605-607; 1987.

22. Waldschmidt, A.; Muller, E. F. A comparison of postnatal thermal physiology and energetics in an altricial (Gerbillus perpallidus) and a precocial (Acomis cahirinus) rodent species. Comp. Biochem. Physiol. 90A:169-181;1988.

23. Webb, D. R.; McClure. P. A. Development of heat production in altricial and precocial rodents: Implications for the energy allocation hypothesis. Physiol. Zool. 62:1293-1315; 1989.

24. West, J. D. Midwinter aggregation in the northern red-backed vole. Clethrionomy's rutilus. Can. J. Zool. 55:1404-1409; 1979. 